\title{
O PLANO NACIONAL DE EDUCAÇÃo COMO ARTICULADOR DA DEMOCRATIZAĈ̃̃ DO ACESSO À UNIVERSIDADE E EMPODERAMENTO DA CLASSE TRABALHADORA
}

\author{
THE NATIONAL EDUCATION PLAN AS ARTICULATOR OF \\ THE DEMOCRATIZATION OF ACCESS TO UNIVERSITY \\ AND EMPOWERMENT OF THE WORKING CLASS
}

\author{
EL PLAN NACIONAL DE EDUCACIÓN COMO ARTICULADOR \\ DE LA DEMOCRATIZACIÓN DEL ACCESO A LA UNIVERSIDAD \\ Y EMPODERAMIENTO DE LA CLASE TRABAJADORA
}

\section{RESUMO}

O objetivo deste ensaio, de caráter teórico e documental, é refletir sobre o(s) conceito(s) de empoderamento da classe trabalhadora, no qual esta se investe de poder, mas com uma importante ressalva: este processo não poderá ser individual e sim coletivo, através do diálogo cooperativo, onde a educação - principalmente a Educação Superior - é a grande protagonista, como articuladora do processo. Nesta esteira, apresenta uma comparação entre o Plano Nacional de Educação (PNE) 2001-2010 e o PNE 2014-2024 com relação às metas voltadas à democratização do acesso à universidade, encontrando que, neste momento, o que de fato podemos afirmar é que não houve muitos avanços no Ensino Superior. Ainda assim, o PNE constitui um importante instrumento jurídico para a democratização do acesso à universidade, que poderá servir como articulador do empoderamento da classe trabalhadora. Repensar a educação significa repensar todo o Estado, uma vez que a política educacional sofre injunções das esferas política, econômica e social. Aprimorando o Estado Brasileiro, se estará avançando para uma concepção mais ampla, que traduzirá uma correlação de forças entre sociedade civil e política, o que significa maior participação social, maior democratização do acesso à universidade e, por consequência, maior empoderamento da classe trabalhadora através, (por que não?) do Ensino Superior. Para tanto, situa-se o importante papel da academia no sentido de preparar educadores e educadoras disseminadores da prática reflexiva, que levará à autonomia e à emancipação.

PALAVRAS-CHAVE: Educação superior. Empoderamento. PNE. Classe trabalhadora. Democratização do acesso à universidade.

\begin{abstract}
The purpose of this essay, theoretical and documental, is to reflect on the concept(s) of empowerment of the working class, in which it invests itself in power, but with an important caveat: this process cannot be individual but collective, through the cooperative dialogue, in which education - especially higher education - is the great protagonist, as articulator of the process. On this track, shows a comparison between the National Education Plan (PNE) 2001-2010 and the PNE 2014-2024 regarding the goals aimed to the democratization of the access to university, finding that, in this moment, what can be affirmed in fact is that there were not many advances in
\end{abstract}

\footnotetext{
${ }^{1}$ Doutoranda em Educação (Unilasalle), Canoas (RS); mestre em Educação (URI-Campus Frederico Westphalen, RS). E-mail: hildegardsjung@gmail.com

${ }^{2}$ Mestre em Educação (URI-Campus Frederico Westphalen, RS). Professor de Educação Física. E-mail: tharlescauduro@hotmail.com

${ }^{3}$ Doutora em Educação e docente e coordenadora do Mestrado em Educação na Universidade Regional Integrada do Alto Uruguai e das Missões (URI/Campus de Frederico Westphalen, RS). E-mail: sudbrack@uri.edu.br
}

Submetido em: 01/08/2016 - Aceito em: 04/09/2016.

\begin{tabular}{l|l|l|l|l|l|l} 
(C) Rev. Inter. Educ. Sup. & Campinas, SP & v.2 & n.2 & p.257-273 & maio/ago. 2016 & ISSN 2446-9424 \\
\hline
\end{tabular}


Higher Education. Still, the PNE is an important legal instrument for the democratization of access to university, which may serve as an articulator of the empowerment of the working class. Rethinking education means rethinking the entire State, since education policy suffers injunctions of political, economic and social spheres. Enhancing the Brazilian State, means moving towards a broader concept, which will translate a correlation of forces between civil society and politics, which means a greater social participation, increased democratization of access to university and consequently, greater empowerment of the working class through (why not?) Higher Education. Therefore, it lies the important role of the academy to prepare educators who disseminate the reflexive practice, which will lead to autonomy and emancipation.

KEYWORDS: Higher Education. Empowerment. PNE. Working class. Democratization of the access to university.

\section{RESUMEN}

El objetivo de este ensayo, de carácter teórico y documental, es reflexionar sobre lo(s) concepto(s) de empoderamiento de la clase trabajadora, en el que ella se inviste de poder, pero con una importante observación: este proceso no podrá ser individual, sino colectivo, a través del diálogo cooperativo, donde la educación principalmente la Educación Superior - es la gran protagonista, como articuladora del proceso. En esta estela, presenta una comparación entre el Plan Nacional de Educación (PNE) 2001-2010 y el PNE 2014-2024 con relación a las metas vueltas a la democratización del acceso a la universidad, encontrando que, en este momento, lo que de hecho podemos afirmar es que no hubo muchos avances en la Enseñanza Superior. Aun así, el PNE constituye un importante instrumento jurídico para la democratización del acceso a la universidad, que podrá servir como articulador del empoderamiento de la clase trabajadora. Repensar la educación significa repensar todo el Estado, puesto que la política educacional sufre influencias das esferas política, económica y social. Perfeccionando el Estado Brasileño, se estará avanzando hacia una concepción más amplia, que traducirá una correlación de fuerzas entre sociedad civil y política, lo que significa mayor participación social, mayor democratización del acceso a la universidad y, por consecuencia, mayor empoderamiento de la clase trabajadora a través, (¿por qué no?) de la Enseñanza Superior. Para ello, se sitúa el importante papel de la academia en sentido de preparar educadores y educadoras diseminadores de la práctica reflexiva, que llevará a la autonomía y a la emancipación.

PALABRAS CLAVE: Educación Superior. Empoderamiento. PNE. Clase trabajadora. Democratización del acceso a la universidad.

\section{PALAVRAS INICIAIS}

A Educação Superior no Brasil tem sua gênese ligada à vinda da Família Real, em 1808, quando o Brasil passou a contar com as Escolas Régias de Medicina na Bahia, a Politécnica (de Engenharia) no Rio de Janeiro e de Direito em Olinda e Recife, tendo em vista a qualificação de mão-de-obra especializada e seguindo o modelo napoleônico francês.

Desde então, coube às elites enviar seus filhos à universidade. A democratização do acesso à educação - e principalmente da Educação Superior - é muito recente no Brasil e seu processo não está ainda livre de tensões.

No sentido da democratização do ensino de uma maneira geral, Burton (2014) nos coloca uma questão relevante: "Qual a relação entre o papel do Estado (liberal democrático) e a formulação de políticas para a educação hoje?” (p. 316). Para refletirmos a respeito, urge que contextualizemos um pouco a formulação das políticas públicas educacionais no Brasil.

Nas últimas décadas, as políticas públicas têm buscado a universalização da Educação Básica brasileira, numa clara intenção de equalizar, especialmente, o acesso ao Ensino Médio

\begin{tabular}{l|l|l|l|l|l|l}
\hline (C) Rev. Inter. Educ. Sup. & Campinas, SP & v.2 & n.2 & p.257-273 & maio/ago. 2016 & ISSN 2446-9424
\end{tabular}


e à Educação Infantil. A expressão desta vontade política consubstancia-se no Fundo de Manutenção e Desenvolvimento da Educação Básica e de Valorização dos Profissionais da Educação (FUNDEB), que substituiu o Fundo de Manutenção e Desenvolvimento do Ensino Fundamental e de Valorização do Magistério (FUNDEF). Ainda, através da Emenda Constitucional $\mathrm{n}^{\circ}$ 59, de 2009 (lei 12796/2013), que alterou os incisos I e VII do artigo 208, prevendo o ensino obrigatório dos quatro aos dezessete anos.

Apesar disso, têm-se ações ainda descentralizadoras, cujos princípios adotados na década de 1990 seguem a cartilha neoliberal do Banco Mundial (BM). Este modelo dá à escola uma falsa autonomia no processo educacional e no campo financeiro, pois "observa-se um processo contraditório: ao mesmo tempo em que a escola adquire maior autonomia, vê-se constrangida a responder aos processos de avaliação externa e a políticas que são definidas centralmente" (COSTA e OLIVEIRA, 2011, p. 728-729). Assim, os autores definem que "a reforma educacional implantada no Brasil nas duas últimas décadas pode estar na contramão de uma educação de qualidade social" (p. 730).

Voltando, porém, à questão da Educação Superior, esta tem seu lastro jurídico, além de outros instrumentos, na formulação do Plano Nacional de Educação (PNE), instituído em 9 de janeiro de 2001, no mandato do então presidente Fernando Henrique Cardoso, por intermédio da Lei $\mathrm{n}^{\circ}$ 10.172. Por outro lado, com relação ao financiamento e gestão das políticas relacionadas à Educação Superior, os avanços mais significativos ocorrem no governo Lula [2003-2010] mas este aprovou o plano governamental PDE em lugar do PNE, mantendo a lógica de políticas governamentais em detrimento de políticas de Estado (DOURADO, 2011).

Para melhor organização deste trabalho, de cunho teórico e documental, o dividimos em quatro partes, a saber: num primeiro momento, faremos um recorrido pelo(s) conceito(s) de empoderamento, partindo da etimologia da palavra anglicana empowerment; A partir daí, refletimos sobre a Educação (Superior) como articuladora de um processo de empoderamento e de emancipação da classe trabalhadora em termos de Freire (1986); Num terceiro momento, propomos uma visão do PNE como política pública e finalizamos com um estudo comparativo entre os PNE 2001-2010 e o PNE 2014-2024 ${ }^{4}$, tendo como referência a Educação Superior. Seria o PNE realmente uma política pública de democratização do acesso à universidade, a qual serviria ao empoderamento da classe trabalhadora brasileira? Sobre esta e outras questões convidamos ao leitor a refletir conosco a partir de agora.

\footnotetext{
4 Esclarecimento ao leitor: O segundo PNE (2011-2020) brasileiro foi enviado pelo governo federal ao Congresso em 15 de dezembro de 2010 (BRASIL, 2014), o qual tramitou durante três anos nas duas casas do Parlamento nacional. Após os ajustes considerados necessários - o levantamento de um "diagnóstico da realidade educacional brasileira que fundamenta a proposta encaminhada" (BRASIL, 1994, p. 6) -, e terminada a tramitação, com sua aprovação, foi realizado o ajuste da data do texto final, estabelecendo o PNE 2014-2024. Desta forma, quando nos referirmos ao projeto de Lei de dezembro de 2010, manteremos a data do documento oficial, 2011-2020. Quando fizermos alusão à lei aprovada n.13.005/2014, que dele se originou, nos referiremos ao PNE 2014-2024.
}

\begin{tabular}{l|l|l|l|l|l|l} 
(C) Rev. Inter. Educ. Sup. & Campinas, SP & v.2 & n.2 & p.257-273 & maio/ago. 2016 & ISSN 2446-9424 \\
\hline
\end{tabular}




\section{O(S) SENTIDO(S) DE EMPODERAMENTO}

Ao pesquisarmos conceitos relacionados ao neologismo de origem anglicana, percebemos que estes se apresentam múltiplos e complexos. Comecemos, pois, pelo significado etimológico do termo, disponível no Collins English Dictionary (2003): 1. the giving or delegation of power or authority; authorization; (a concessão ou delegação de poder ou autoridade; autorização); 2. the giving of an ability; enablement or permission (a doação de uma habilidade; habilitação ou permissão). Buscando seu significado em português, encontramos a definição do Dicionário Aurélio on-line: "1. Ato ou efeito de empoderar ou empoderar-se". Para a palavra empoderar, lê-se no mesmo sitio: "Dar ou adquirir poder ou mais poder.". Notamos uma sensível distinção na hermenêutica da palavra em seu sentido original na língua inglesa, onde o termo designa conceder, doar autoridade ou poder. Já em Língua Portuguesa, seu significado apresenta-se mais amplo ao nosso entender: "empoderar" ou "empoderar-se", como verbo transitivo ou intransitivo, quando além de conceder poder, é possível entender também investir-se de poder, num sentido de autoempoderamento. Mais adiante retomaremos estes conceitos.

Segundo Baquero (2012), diferentes áreas do conhecimento têm utilizado o termo empowerment, como a "educação, sociologia, ciência política, saúde pública, psicologia comunitária, serviço social, administração" (p. 174), embora suas raízes estejam na Reforma Protestante, iniciada por Martinho Lutero (1552), no século XVI. Lutero traduziu a Bíblia para o alemão, até então somente disponível em latim, como uma forma de possibilitar ao povo simples e pouco culto ter acesso às Sagradas Escrituras, promovendo seu "empoderamento".

Na segunda metade do século XX, o termo volta à tona nos Estados Unidos, com a Empowerment Tradition (Tradição do Empoderamento), vinculado a movimentos emancipatórios de grupos que reivindicavam seu reconhecimento, como os negros, homossexuais, mulheres, mulheres, deficientes, etc., nos anos 1960. Nos anos 1970 sofre influência dos movimentos de auto-ajuda, a partir de 1980 da psicologia comunitária e a partir da década de 1990 distintas esferas da vida social passam a fazer uso do conceito de empowerment, a saber: saúde, política, justiça e ação comunitária.

Ainda Baquero (2012) refere que, atualmente, três esferas têm se apropriado do termo empowermemt: a) a sociedade norte-americana, "que tem sido cooptada pelo individualismo e pelas noções individuais de progresso, orientada para o self madem man (o homem que se faz pelo seu próprio esforço pessoal).” (p. 177); b) O empoderamento organizacional, supondo autonomia e participação, visando melhor desempenho e maior produtividade; c) Empoderamento comunitário, cujo objetivo é o de capacitar grupos ou indivíduos desfavorecidos, no sentido de conquistarem cidadania plena e defesa de seus interesses para influenciar as ações do Estado. 
Por outro lado, Gohn (2004) alerta que a expressão empowerment estaria se tornando um jargão das políticas públicas e dos seus analistas, podendo referir-se a aspectos que tenham a capacidade de "gerar processos de desenvolvimento autossustentável, com a mediação de agentes externos - os novos educadores sociais - atores fundamentais na organização e no desenvolvimento de projetos.” (p. 23).

Pesquisadores como Valoura (2006) trazem Paulo Freire (1921-1997) como o autor do termo empoderamento em seu sentido transformador, mas por outro lado, temos o amplo estudo realizado por Roso e Romanini (2014) que, ao analisarem 16 obras $^{5}$ de Freire, encontraram o termo empowerment em somente uma delas: Medo e ousadia (FREIRE e SHOR, 1986). "Paulo Freire emprega 16 vezes o termo neste livro. Em três dessas, Freire demonstra preocupação com o uso indiscriminado do conceito" (ROSO e ROMANINI, 2014, p. 87), porque, para Freire (1986), a questão remonta à "autonomia individual, ao individualismo e à autolibertação” (FREIRE e SHOR, 1986, p.135).

Ainda nesta obra freireana encontramos um importante esclarecimento:

A questão do empowerment da classe trabalhadora, através de suas próprias experiências, sua própria construção de cultura, se empenha na obtenção do poder político. Isto faz de empowerment muito mais do que um invento individual ou psicológico. Indica um processo político das classes dominadas que buscam a própria liberdade da dominação um longo processo histórico de que a educação é uma frente de luta (FREIRE e SHOR, 1986, p. 72).

Dito isso, voltamos à hermenêutica do termo que abordamos no início deste trabalho: empoderar e empoderar-se. Em nosso entendimento, Freire (1986) se refere ao segundo significado, dentro do qual a classe trabalhadora se investe de poder, mas com uma importante ressalva: este processo não poderá ser individual e sim coletivo, através do diálogo cooperativo e no qual a educação é a grande protagonista.

Chegamos, pois, ao ponto de que a educação se articula como frente de luta para o empoderamento da classe trabalhadora. E por que não a Educação Superior? Mas a educação poderia ser encarada como um passaporte ao empoderamento? Sobre esta questão discorremos a seguir.

\footnotetext{
${ }^{5}$ Os autores pesquisaram o termo nas seguintes obras de Paulo Freire: A importância do ato de ler: em três artigos que se completam (1989); Ação cultural para a liberdade (1981); Extensão ou comunicação? (1983b); Pedagogia da autonomia: saberes necessários à prática educativa (1996); Pedagogia da indignação: cartas pedagógicas e outros escritos (2000); Pedagogia do Oprimido (1983a); Professora sim, tia não. Cartas a quem ousa ensinar (1997); Professora sim, tia não. Cartas a quem ousa ensinar (1997); Educação e mudança (1979); Pedagogia. Diálogo e conflito (Freire, Gadotti, \& Guimarães, 1995); Cartas a Guiné-Bissau (1978); Por uma pedagogia da pergunta (Faundez \& Freire, 1985); Pedagogia da esperança (1992); Medo e ousadia (Freire \& Shor, 1986); Conscientização (1979); Educação como prática da liberdade (1967). "Das 29 vezes em que ele é citado, dez advêm de Ira Shor, uma compõe o sumário, outra é mencionada em nota de rodapé e outra aparece no título do capítulo quatro O que é método dialógico de ensino? O que é uma pedagogia situada e empowerment? Ou seja, Paulo Freire emprega 16 vezes o termo neste livro" (ROSO E ROMANINI, 2014, p.
} 87).

\begin{tabular}{l|l|l|l|l|l|l} 
(C) Rev. Inter. Educ. Sup. & Campinas, SP & v.2 & n.2 & p.257-273 & maio/ago. 2016 & ISSN 2446-9424
\end{tabular}




\section{A EDUCAÇÃO COMO POSSIBILIDADE DE EMANCIPAÇÃO E DE EMPODERAMENTO}

Propomos uma rápida reflexão a respeito da própria educação enquanto política pública, pois reza nossa Carta Magna de 19889, em seu artigo 205, que a educação é direito de todos e "dever do Estado e da família [...] visando ao pleno desenvolvimento da pessoa, seu preparo para o exercício da cidadania e sua qualificação para o trabalho." (BRASIL, 1988 - grifo nosso). Igualmente, o artigo 208 garante que o "dever do Estado com a Educação" (id.) se consumará garantindo "III - atendimento educacional especializado aos portadores de deficiência, preferencialmente na rede regular de ensino; IV - atendimento em creche e préescola às crianças de 0 a 6 anos de idade." (id.).

Posto que, como apontamos, políticas públicas referem-se aos 'fazeres' do Estado (numa definição minimalista ao extremo) e a educação se configura "dever do Estado" (BRASIL, 1988), entendemos a educação como política pública, pois

\footnotetext{
Não se pode esquecer que a escola e principalmente a sala de aula, são espaços em que se concretizam as definições sobre política e o planejamento que as sociedades estabelecem para si próprias [...] O cotidiano escolar, portanto, representa o elo final de uma complexa cadeia que se monta para dar concretude a uma política - a uma policy - entendida aqui como programa de ação (AZEVEDO, 1997, p. 59).
}

Apesar de a origem das políticas educacionais não ser o escopo deste trabalho, parecenos importante salientar que, com relação à criação de uma política educacional, esta normalmente parte de uma demanda, mas sua verdadeira origem poderá ser proveniente de pressão de organizações internacionais, organizações privadas e/ou organizações nãogovernamentais. As políticas públicas surgem, caracterizam-se e implantam-se normalmente em meio a tensões e conflitos sociais e a elas se atribui a capacidade de superação destes embates no lastro da organização do Estado. Com as políticas educacionais não é diferente, estas, "por mais que aparentem um caráter benfeitor, traduzem uma relação de poder de um grupo que se sobrepõe ao outro" (SUDBRACK, 2014, p. 171).

De qualquer forma, a política educacional necessita de uma base jurídica, seja da esfera municipal, estadual ou da União, que toma corpo a partir de uma lei, um decreto com força de lei, um decreto executivo ou um pronunciamento judicial. Após a sua criação, seus efeitos serão sentidos na prática educacional, podendo gerar efeitos inesperados.

Segundo Fávero et. Al (2013), vivemos uma época paradoxal na educação, já que, por um lado, ao mesmo tempo em que há um maior investimento na pasta e cresce o acesso ao ensino superior e à pós-graduação, por outro lado diversas contradições "obstaculizam o ato da educação ocupar o lugar que lhe compete na realização de uma sociedade justa e democrática" (p. 278). Os autores continuam, reafirmando o desafio atual da escola, que precisa, no processo de socialização do saber, reposicionar-se na sociedade da informação, o que implica na urgente redefinição das características identitárias, tanto da escola em si, como dos seus docentes e gestores.

\begin{tabular}{l|l|l|l|l|l|l} 
(C) Rev. Inter. Educ. Sup. & Campinas, SP & v.2 & n.2 & p.257-273 & maio/ago. 2016 & ISSN 2446-9424
\end{tabular}


Considerando a escola como espaço democrático e de decisões, passando pela questão da participação, chegamos ao conceito de emancipação, cuja aspiração é a "construção de conexões entre a prática e o contexto social mais amplo, o qual provoca autonomia nos educandos que devem transformar a realidade na mesma proporção da sua emancipação" (NOGARO e SILVA, 2015, p.69).

Com relação à concepção da escola enquanto espaço democrático de participação, Sudbrack (2014) destaca o papel do gestor como "fundamental para o acontecimento efetivo de práticas democráticas buscando a aprendizagem de todos os estudantes" (p. 116). A autora complementa referindo que, para isto, o ambiente deverá ser positivo e precisa promover a participação de todos.

Na construção de uma agenda educativa que possa mobilizar no sentido de uma ação humana transformadora, Teodoro (2011) aponta três pontos de partida: a) o primeiro diz respeito à condição de igualdade, no sentido de que "todos somos cidadãos do mesmo mundo" (p. 137), lutando pelo bem-estar e que para isso torna-se necessário lutar contra todos os tipos de injustiça e de exclusão; b) o segundo, ainda relacionado com a questão da igualdade, mas como princípio de reconhecimento das diferenças, que o autor denomina "o antídoto do medo do outro" (p. 132), remete à igualdade de oportunidades; c) o terceiro e último ponto é a escola de excelência para todos, na qual não se dicotomiza a pedagogia da performance.

Em Weyh (2011) encontramos ainda a questão da educação como possibilidade de reflexão crítica, mas para ensinar a pensar criticamente, o educador também precisa fazê-lo. A emancipação, ainda que seja a dos educadores e educadoras, ensina o autor, acontece na dialogicidade entre os sujeitos "como o futuro, que não estão dados, são apenas possibilidades que precisam ser construídas". (p. 159).

Assim, considerando a educação como política pública e espaço que protagoniza o diálogo no sentido de empoderamento da classe trabalhadora, passaremos a refletir sobre o Plano Nacional de Educação (PNE) como possibilidade de lastro jurídico para a efetivação deste processo e democratização do acesso à universidade, recorrendo brevemente sua origem e, a seguir, estabelecendo uma comparação entre o PNE 2001-2010 para o PNE 2014-2024, tendo como referência o Ensino Superior.

\section{O PNE COMO POLÍTICA PÚBLICA E A EDUCAÇÃo SUPERIOR}

A história da educação brasileira é marcada por disputas de projetos com concepções distintas do papel do Estado e do planejamento, da relação entre os entes federados e da lógica de gestão e organização. A discussão em torno do Plano Nacional de Educação (PNE), suscita a consideração de seus diversos sentidos e concepções que, implicados na definição do termo ao longo do tempo, servem como base para a compreensão do assunto nos dias 
atuais. Suas origens fornecem subsídios para compreender seu espaço e papel no campo das políticas educacionais brasileiras.

Segundo Dourado (2011), a caminhada do planejamento e das políticas educacionais no Brasil sempre esteve marcada por políticas governamentais e não por políticas de Estado. $\mathrm{O}$ autor destaca, entre outros, alguns marcos importantes:

a) Em 1932 acontece o lançamento do Manifesto dos Pioneiros da Educação Nova, influenciando a Constituição Brasileira de 1934, a qual estabeleceu, além de fixar o Plano Nacional de Educação, coordenar e fiscalizar sua aplicação. Em 1937, o Estado Novo negligencia o projeto e, através da Constituição de 1937, atribui à União a fixação de bases e diretrizes para a "formação física, intelectual e moral da infância e da juventude". Já de 1939 a 1945, o governo Vargas elabora um plano quinquenal, mas este não se concretiza. Com a Constituição de 1946, cabe à União legislar sobre “diretrizes e bases da educação nacional”. No governo Kubistcheck [1956-1961] implanta-se o Plano Nacional de Desenvolvimento (Programa de Metas) e surge pela primeira vez a relação educação-desenvolvimento (Dourado, 2011).

b) Na década de 1964, o governo militar desarticula a LBD e entra o pensamento tecnocrático ${ }^{6}$; De 1964 a 1966, o Plano Trienal foi substituído pelo Programa de Ação Econômica do governo e por planos decenais, estratégicos e de desenvolvimento. Até 1974, os planos do regime militar afastam-se da opção de oferecer a educação para o maior número possível de educandos e assume um estilo economicista, o qual situa a educação no processo de desenvolvimento.

c) De 1980 a 1985, o III Plano Nacional de Desenvolvimento reflete o novo cenário de redução da interferência dos tecnocratas e cresce a mobilização social em prol da saúde e da educação, entretanto, ainda vigora o modelo tecnicista de desenvolvimento. Foi em 1988 que a Constituição Federal trouxe uma nova configuração ao papel e à autonomia dos entes federados e municípios, reforçando o federalismo, por meio de leis complementares e normas de colaboração entre união e estados, Distrito Federal e municípios, e ainda uma concepção de administração pública direta e indireta marcada pelos princípios de legalidade, impessoalidade, moralidade, publicidade e eficiência (Dourado, 2011).

d) O Art. 214 da Constituição Federal de 1988, por meio da Emenda Constitucional 59/2009, aponta para um significativo avanço na atual legislação, garantindo o estabelecimento do Plano Nacional de Educação (PNE), de duração decenal, com o objetivo de articular o sistema nacional de educação em regime de colaboração e

\footnotetext{
6“Pensamento prático, objetivo, operativo, racional e abstrato. Implica um modo particular de desagregação dos conteúdos políticos e as condições reais de existência das pessoas, os grupos e a vida social em geral" (BAUTISTA, 2013, p. 26 - tradução nossa).
} 
definir diretrizes, objetivos, metas e estratégias de implementação para assegurar a manutenção e desenvolvimento do ensino em seus diversos níveis, etapas e modalidades por meio de ações integradas dos poderes públicos das diferentes esferas federativas que conduzem a (EC 59/2009):

I - erradicação do analfabetismo; II- universalização do atendimento escolar; III melhoria da qualidade de ensino; IV - formação para o trabalho; V - promoção humanística, Científica e tecnológica do País; VI - estabelecimento de meta de aplicação de recursos públicos em educação como proporção do produto interno bruto (BRASIL, 2009, art. 2014)

É importante situar que todos os antecedentes históricos indicam os caminhos e as opções hegemônicas adotadas no planejamento e nas políticas educacionais de governo. Em 9 de janeiro de 2001, no mandato do então presidente Fernando Henrique Cardoso, foi sancionada a Lei $\mathrm{n}^{\mathrm{o}}$ 10.172, responsável pela aprovação do Plano Nacional de Educação (PNE), não possuindo referência-base do planejamento e das políticas públicas. É no governo Lula que houve avanços significativos, principalmente no que se refere ao financiamento e gestão das políticas relacionadas à Educação Básica e à Educação Superior, mas este aprovou o plano governamental PDE em lugar do PNE, mantendo a lógica de políticas governamentais em detrimento de políticas de Estado (DOURADO, 2011).

\section{O PNE 2001-2010 E O PNE 2014-2024 COM RELAÇÃO AO ENSINO SUPERIOR - LIMITES E POSSIBILIDADES DE DEMOCRATIZAÇÃO DO ACESSO À UNIVERSIDADE}

Falar do PNE requer certamente refletir sobre a Lei de Diretrizes e Bases (LDB) para o campo educacional. O intuito da mesma é oferecer uma educação igualitária como direito de todos. Foi proposto pelo então Ministro da Educação Clemente Mariani o Projeto de Lei e Diretrizes e Bases da Educação Nacional, que resultou (após longo processo de tramitação) na primeira Lei de Diretrizes e Bases no 4.024/61, sancionada em 20 de dezembro de 1961. Esta foi modificada por emendas e artigos, sendo reformada pelas leis 5.540/68, 5.692/71 e posteriormente, substituída pela LDB 9.394/96 (WIZIACK, 2010).

Percebe-se a importância da LBD, fixando os objetivos, os meios e as condições de planejamento por meio dos quais o poder público coordena os esforços da Nação no campo educativo. Mas, a criação do PNE, para Saviani (2007, p.160) "resulta, portanto, mais importante do que a própria LDB". De forma breve e sucinta, o PNE tem como objetivo estabelecer diretrizes e metas para a educação em todos os níveis num período de 10 anos. $\mathrm{O}$ primeiro criado no Brasil foi o PNE 2001-2010. Mas o que ele mencionava sobre a Educação Superior e o que ocorreu na prática?

O primeiro Plano Nacional de Educação teve 295 metas estabelecidas, estando entre elas estava a destinação de 7\% do Produto Interno Bruto (PIB) para a educação, a erradicação do analfabetismo, o combate à evasão escolar, a ampliação do acesso ao Ensino Superior, etc.

\begin{tabular}{l|l|l|l|l|l|l} 
(C) Rev. Inter. Educ. Sup. & Campinas, SP & v.2 & n.2 & p.257-273 & maio/ago. 2016 & ISSN 2446-9424 \\
\hline
\end{tabular}


Mas, observando os dados apontados por Saraiva (2011), resultam caracterizadas relevantes conclusões:

- A evasão escolar aumentou entre 2006 e 2008, e o índice passou de $10 \%$ para 13,2 \% - a meta do PNE era reduzir $5 \%$ ao ano -.

- O taxa de analfabetismo segue muito alta $-9,7 \%$ em $2010^{7}$. Em 2000, a taxa era de $13,6 \%$ e a meta do PNE estabelecia a erradicação do analfabetismo em 2010. A comparação com outros países da América Latina não deixa dúvidas sobre o tamanho do problema: no Uruguai, na Argentina e no Chile as taxas variam entre $2 \%$ e $4 \%$.

- O número de jovens no Ensino Superior permanece baixo: $14,4 \%{ }^{8}$ em 2009. A meta do PNE era chegar a 30\% dos jovens na universidade. Neste ritmo, o país demoraria 59 anos para cumprir a meta. O Brasil também é campeão de exclusão neste aspecto, pois nos outros países da América Latina a porcentagem de jovens no Ensino Superior é muito maior: Argentina - 40\%; Chile - 20,6\%; Venezuela - 26\%; e Bolívia - 20,6\%.

- Na última década, o Ensino Superior privado cresceu duas vezes mais que o público. A meta do PNE era ofertar $40 \%$ das vagas universitárias na rede pública, porém, em 2002 esse índice era de $29 \%$ e em 2010 de $25 \%$.

- Outro fator é a desigualdade no acesso ao Ensino Superior, caracterizada como altíssima. Somente 5,6\% dos jovens que tem rendimentos mensais per capita de meio a um salário mínimo cursam a universidade. Para os jovens que se encontram na faixa de cinco salários mínimos ou mais, a porcentagem sobe 10 vezes: 55,6\% frequentam o Ensino Superior.

De acordo com Saraiva (2011), o PNE 2001-2010 acabou por transformar-se em um fracasso, pelo fato de que $2 / 3$ das metas programadas acabaram não sendo cumpridas. Em grande parte dos discursos sobre o fracasso foi apontado o excesso de metas, falta de indicadores que pudessem aferir o andamento delas, ausência de planejamento dos estados e municípios, entre outros. Entre os especialistas, porém, inclusive apoiadores do governo, a razão central do fracasso foi a ausência de recursos investidos na educação.

Ao observarmos as estatísticas elencadas do antigo PNE, constatamos que há fragilidades no sentido de alcançarmos uma educação com eficiência e qualidade, e que sirva de instrumento de empoderamento da classe obreira. Chamamos a atenção para o processo de elaboração do PNE 2011-2020, que teve a responsabilidade da Conferência Nacional de Educação - CONAE, a qual se reuniu em Brasília em 2010 com um enfoque diferenciado e

\footnotetext{
${ }^{7}$ Pesquisa Nacional por Amostra de Domicílios (Pnad) do Instituto Brasileiro de Geografia e Estatística (IBGE) 2010.

${ }^{8}$ Análise do Instituto de Pesquisa Econômica Aplicada (Ipea) a partir dos dados da Pesquisa Nacional por Amostra de Domicílios (Pnad/IBGE).

\begin{tabular}{l|l|l|l|l|l|l} 
(C) Rev. Inter. Educ. Sup. & Campinas, SP & v.2 & n.2 & p.257-273 & maio/ago. 2016 & ISSN 2446-9424
\end{tabular}
}


bem organizado, sendo coordenado pelo MEC, e recebendo aportes, para sua elaboração, vindos de empresários, do governo e dos trabalhadores ${ }^{9}$ (Saraiva, 2011). O que chama a atenção é que esses representantes envolvidos não possuíam nenhuma relação com os estudantes, pessoas que trabalham com a educação, ou com movimentos sociais. Não mantinham sequer compromisso com a educação pública e com os interesses dos trabalhadores e do povo pobre brasileiro.

Com base no novo PNE, uma nova reforma foi elaborada. O que antes era um documento com 100 páginas, no novo estabeleceu-se com 14 páginas e 20 metas. Cinco das vinte metas tratam especificamente de atividades da Educação Superior, as quais serão analisadas neste trabalho. Com base no cenário atual e nos desafios a serem enfrentados, ponderamos seu papel, como antes referido, no sentido de facilitar o acesso da classe trabalhadora à universidade, num movimento de empoderamento.

A primeira delas, a Meta 12: propõe a elevação da taxa bruta de matrícula na Educação Superior para 50\% e a taxa líquida para 33\% da população de 18 a 24 anos, assegurada a qualidade da oferta e expansão para, pelo menos, $40 \%$ das novas matrículas, no segmento público.

Tendo como suporte teórico Lima e Ramos ${ }^{10}$ (2013), podemos observar que em 2011, 6,4 milhões de alunos foram matriculados no Ensino Superior, destes $26 \%$ nas instituições públicas e $74 \%$ nas Instituições de Ensino Superior (IES) privadas, correspondendo a uma taxa líquida de 14,6\% e uma taxa bruta de matrículas de 27,8\%. Podemos observar que, além disso, há metas que, apesar de não cumpridas, foram esquecidas e seguem citadas no PNE 2014-2024, como a oferta de ao menos 40\% das vagas do Ensino Superior nas instituições públicas. O objetivo de incluir 30\% dos jovens de 18 a 24 anos na universidade em 2010 transformou-se em $33 \%$ para 2024, ou seja, a grande maioria delas é uma mera repetição das metas não cumpridas.

A Meta 13: propõe elevar a qualidade da educação superior e ampliar a proporção de mestres e doutores nas instituições de Educação Superior para no mínimo $75 \%$ do corpo docente em efetivo exercício, sendo, do total, $35 \%$ de doutores.

Nosso cenário atual mostra um total de 345 mil docentes atuantes - 28\% doutores, $38 \%$ com mestrado e $34 \%$ com graduação/especialização. Para que a meta seja atingida, precisamos promover um acréscimo de 9\%. De certa forma, esta aparenta ser menos complexa do que a meta anterior no sentido de sua consecução. Porém, deve ser articulada com a próxima meta, - a de formação de mestres e doutores - e levar em conta que essa

\footnotetext{
${ }^{9}$ A Confederação Nacional dos Estabelecimentos de Ensino, a Confederação Nacional dos Empresários e a Confederação Nacional da Indústria fizeram parte da Comissão Organizadora da CONAE.

10 José Fernandes de Lima é presidente do Conselho Nacional de Educação e professor aposentado da Universidade Federal de Sergipe (UFS). Mozart Neves Ramos é membro do Conselho Nacional de Educação (CNE) e do Conselho de Governança do Todos Pela Educação, e professor da Universidade Federal de Pernambuco (PE).
}

\begin{tabular}{l|l|l|l|l|l|l} 
(C) Rev. Inter. Educ. Sup. & Campinas, SP & v.2 & n.2 & p.257-273 & maio/ago. 2016 & ISSN 2446-9424 \\
\hline
\end{tabular}


formação ocorre de forma assimétrica quanto à distribuição regional (LIMA e RAMOS, 2013).

A Meta 14: trata de elevar gradualmente o número de matrículas na pós-graduação stricto sensu, de modo a atingir a titulação anual de 60 mil mestres e 25 mil doutores.

Uma das poucas metas cumpridas no antigo PNE corresponde ao aumento de mestres formados anualmente (de 2002 a 2012), que passou de 24 mil para 47 mil, tendo um crescimento de $102 \%$. Portanto, se o Brasil continuar nesse ritmo de crescimento, alcançar a meta programada para o novo PNE, atingindo os 60 mil mestres, não será difícil. Ainda assim, lograr o almejado na classe de doutores será de certa forma difícil, afinal, consta que no Brasil (até 2012) temos aproximadamente 14 mil. A maior distribuição bolsas de estudos e uma maior quantidade de vagas para essa especialização certamente contribuirá para o alcance da meta programada para 2024 (LIMA e RAMOS, 2013).

Meta 15: garantir, em regime de colaboração entre União, os estados, o distrito federal e os municípios no prazo de um ano de vigência deste PNE, política nacional de formação dos profissionais da educação de que tratam os incisos I, II e III do caput do art.61 da Lei $n^{\circ} 9.394$, de 20 de dezembro de 1996, assegurando que todos os professores da educação básica possuam formação específica de nível superior, obtida em curso de licenciatura na área de conhecimento em que atuam.

De certa forma, essa meta é questionada atualmente pelos docentes, no sentido que nossa educação necessita de uma melhor qualidade, começando pela integração de pessoas especializadas e capacitadas para atender a tais necessidades. Para atingirmos os objetivos, necessitamos a expansão e incentivo da especialização docente, ou seja, é preciso trabalhar junto às redes públicas estaduais e municipais para que sejam previstos os concursos públicos necessários, sem esquecer que além de suprir a demanda, é necessário um relevante trabalho pela valorização da profissão do professor, caso contrário, a evasão dos cursos de licenciatura continuará expressiva. Lima e Ramos (2013) mencionam que em 2011 essa etapa de ensino empregou cerca de 2 milhões de professores, dos quais $78 \%$ possuíam formação superior, o que significa que há a necessidade formar 450 mil novos professores, atingindo particularmente as áreas identificadas como carentes.

Meta 16: formar, em nível de pós-graduação, 50\% dos professores da Educação Básica, até o último ano de vigência deste PNE, e garantir a todos (as) os (as) profissionais da Educação Básica formação continuada em sua área de atuação, considerando as necessidades, demandas e contextualizações dos sistemas de ensino.

Conforme apontado nas considerações da meta 15, o Brasil possui aproximandamente dois milhões de professores, sendo que um milhão deverá concluir a especialização até o final do atual PNE. De certa forma, é preciso que as secretarias de educação liberem seus profissionais para cursarem os mestrados e doutorados, e procedam os ajustes necessários nos

\begin{tabular}{l|l|l|l|l|l|l} 
(C) Rev. Inter. Educ. Sup. & Campinas, SP & v.2 & n.2 & p.257-273 & maio/ago. 2016 & ISSN 2446-9424
\end{tabular}


planos de carreira, garantindo um aproveitamento mais otimizado desses profissionais. $\mathrm{O}$ que vivenciamos atualmente é a não valorização da qualificação docente e a falta de tempo para pensar na especialização, uma vez que o horário disponível precisa ser reservado para o planejamento das aulas.

Após essa análise do antigo e o novo PNE para o Ensino Superior, é possível perceber que os desafios são expressivos e exigirão um plano de articulado e bem elaborado entre governos e instituições formadoras, para que essas metas possam ser efetivamente alcançadas no atual PNE. Em outras palavras: para que uma maior parcela da classe trabalhadora tenha acesso à Educação Superior, como forma de empoderamento, o PNE estabelece metas de grande relevância, porém, a sua consecução depende de inúmeros fatores de ordem ideológica, política e, principalmente, financeira.

Nesse momento, o que de fato podemos afirmar é que desde o estabelecimento do primeiro PNE não houve muitos avanços no Ensino Superior. Ainda assim, como referimos, o PNE constitui um importante instrumento jurídico para a democratização do acesso à universidade, podendo servir como articulador do empoderamento da classe trabalhadora. É necessária maior autonomia da educação pública superior, uma vez que as políticas não garantem independência na gestão financeira às universidades, como determina o art. 207 da Constituição. Também, conforme Dourado (2011, p. 292-293) "é fundamental a efetivação constitucional da autonomia universitária, para que estabeleçam seus próprios processos de gestão e os dos recursos financeiros colocados à sua disposição".

\section{PALAVRAS FINAIS}

Em alguma medida, a Educação Superior necessita de um aprimoramento no processo avaliativo, tornando-o abrangente, promovendo o desenvolvimento institucional e a melhoria da qualidade da educação como lógica constitutiva do processo emancipatório, considerando a autonomia da IES, indissociabilidade entre ensino, pesquisa e extensão (CONAE, 2010). Acreditamos que, com a diminuição das desigualdades sociais e regionais, e a elevação da renda per capita no Brasil, os desafios educacionais sejam diminuídos. Um desses caminhos seria o cumprimento das metas do PNE e, dentre uma das mais significativas, a aplicação de $10 \%$ do Produto Interno Bruto (PIB) à educação, melhorando a distribuição de recursos para que a qualidade do ensino seja incrementada.

Entender a educação enquanto política pública na articulação das demais políticas é fundamental para que esta se efetive como política de Estado. Para tanto, é necessário avançar no planejamento e na gestão educacional, atualizando os indicadores para que estes contribuam no monitoramento e avaliação do PNE, e para que garantam programas entre os distintos entes federados com maior organicidade.

Repensar a educação significa repensar todo o Estado, uma vez que a política educacional sofre injunções das esferas política, econômica e social. Aprimorando o Estado

\begin{tabular}{l|l|l|l|l|l|l}
\hline (c) Rev. Inter. Educ. Sup. & Campinas, SP & v.2 & n.2 & p.257-273 & maio/ago. 2016 & ISSN 2446-9424 \\
\hline
\end{tabular}


Brasileiro, se estará avançando para uma concepção mais ampla, que traduzirá uma correlação de forças entre sociedade civil e política, o que significa maior participação social e maior empoderamento, como antes citamos.

Podemos concluir que, ao examinarmos a palavra empowerment, se tomarmos como esteira o sentido de "empoderar-se" na direção de "investir-se" de poder, em termos de Freire (1987), que refere este processo não como um ato individual e isolado de um indivíduo, mas como aquele que opera na coletividade do diálogo, a Educação - e por que não a Educação Superior, antes somente destinada às elites? - se apresentam como ferramentas valiosas neste processo.

Apesar de lentamente, caminhamos para uma maior democratização de acesso à universidade e o PNE se tornou um instrumento importante no sentido de fixar metas para os próximos anos (até 2024). Comparando os últimos dois planos no que se refere à Educação Superior (PNE 2001-2010 e PNE 2014-2024) percebemos que não avançamos muito, embora tenhamos repetido as metas não alcançadas.

Cabe agora ao cidadão empoderar-se e deixar de lado a cultura do silêncio que ainda retrai a classe trabalhadora e fazer valer seus direitos no sentido de lutar para que se cumpram as metas traçadas para o Ensino Superior e aqui incluímos o papel da academia, que forma educadores e educadoras disseminadores da prática reflexiva, pois a "emancipação não é apenas uma prática emancipada, antes, deve integrar a consciência do sujeito, solidificar-se no seu pensar para agir com autonomia continuamente" (NOGARO e SILVA, 2015, p. 94).

\section{REFERÊNCIAS}

ANPED. Por um Plano Nacional de Educação (2011-2020) como política de Estado. Rio de Janeiro. Armazém das Letras Gráfica e Editora Ltda, 2011.

BAQUERO, Rute Vivian Angelo. Empoderamento: instrumento de emancipação social? uma discussão conceitual. Revista Debates, Porto Alegre, v. 6, n. 1, p.173-187, jan.-abr. 2012. PP. 173-187, 2012. Disponível em:

http://www.seer.ufrgs.br/index.php/debates/article/view/26722/17099. Acesso em 30.05.2015.

BRASIL. Constituição da República Federativa do Brasil. Brasília, 1988.

BRASIL. Plano Nacional de Educação 2001-2010. Lei no 10.172, de 9 de Janeiro de 2001.Disponível em:〈http://www.planalto.gov.br/ccivil_03/leis/leis_2001/110172.htm>. Acesso em 24 de janeiro de 2016.

BRASIL. Plano Nacional de Educação 2014-2024. Lei no 13.005 , de 25 de junho de 2014. Disponível em < http://www.planalto.gov.br/ccivil_03/_ato2011-2014/2014/lei/113005.htm> Acesso em 06 de abril de 2016. 
BRASIL. Presidência da República, Ministério da Educação. CONAE 2010 - Conferência Nacional de Educação. Brasília, DF: CONAE, abril de 2010.

BURTON, Guy. Teorizando o Estado e a Globalização na política e políticas educacionais. Práxis Educativa, Vol. 9, N. 2, 2014. Disponível em: http://www.revistas2.uepg.br/index.php/praxiseducativa/article/viewArticle/6386. Acesso em: 4 abr. 2015.

COLLINS. English Dictionary. Harper Collins Publishers, New York City, 2003.

COSTA, Gilvan Luiz Machado. OLIVEIRA, Dalila Andrade. Trabalho docente no ensino médio no Brasil. Perspectiva, Florianópolis, v. 29, n. 2, 727-750, jul./dez. 2011. Disponível em: http://www.perspectiva.ufsc.br/. Acesso em: 16 nov. 2014.

DIAS, Reinaldo. Ciência política. São Paulo: Atlas, 2010.

DICIONÁRIO AURÉLIO Online. Disponível em http://dicionariodoaurelio.com/. Acesso em: 30 maio 2015.

DOURADO, Luiz Fernando. Plano Nacional de Educação (2011-2020): avaliação e perspectiva - 2.ed. - Goiânia: Editora UFG; Belo Horizonte: Autêntica Editora, 2011.

ESPINOZA, Oscar. Archivos analíticos de políticas educativas. v.17, n.8, 15 abr., 2009.

FÁVERO, Altair Alberto; TONIETTO, Carina; ROMAN, Marisa Fátima. A formação de professores reflexivos: a docência como objeto de investigação. Revista Educação. Santa Maria, v. 38, n.2, p. 277-288, maio/ago. 2013. Disponível em:

http://cascavel.cpd.ufsm.br/revistas/ojs-2.2.2/index.php/reveducacao/article/view/5483/5466. Acesso em: 4 abr. 2015.

FREIRE, Paulo. Pedagogia do oprimido. 17.ed. Rio de Janeiro: Paz e Terra, 1987.

FREIRE, Paulo; SHOR, Ira. Medo e ousadia: o cotidiano do professor. Trad.: Adriana Lopes. 2.ed. Rio de Janeiro: Paz e Terra, 1986.

GOHN, Maria da Glória. Empoderamento e participação da comunidade em políticas sociais. Saúde e Sociedade, v.13, n.2, p.20-31, maio-ago 2004. Disponível em: https://www.google.com.br/url?sa=t\&rct=j\&q=\&esrc=s\&source=web\&cd=1\&cad=rja\&uact= $8 \&$ ved=0CB0QFjAA\&url=http $\% 3 \mathrm{~A} \% 2 \mathrm{~F} \% 2 \mathrm{Fwww} \cdot$ revistas.usp.br $\% 2 \mathrm{Fsausoc} \% 2 \mathrm{Farticle} \% 2 \mathrm{~F}$ download\%2F7113\%2F8586\&ei=101rVcHeLsyVNqGJgvgB\&usg=AFQjCNGcfnd8ylBSvoe 4eYm52ASaPfLCxg\&sig2=zBh1tWsdhbOZs_mZIw6n8A\&bvm=bv.94455598,d.cWc .

Acesso em: 30 maio 2015.

LIMA, José Fernandes de; Ramos, Mozart Neves. Os desafios da Educação Superior para a próxima década. Artigo publicado no Correio Braziliense em 3/10/2013. Disponível em: $<$ http://www.observatoriodopne.org.br/metas-pne/12-ensino-superior/analises/os-desafios-daeducacao-superior-para-a-proxima-decada>. Acesso em: 27 out. 2014. 
NOGARO, Arnaldo e SILVA, Henriqueta Alves. Professor reflexivo: prática emancipatória?. Curitiba, PR: CRV, 2015.

OLIVEIRA, Adão. Políticas públicas educacionais: conceitos e contextualização numa perspectiva didática. In: OLIVEIRA, Adão; PIZZIO, Alex; FRANÇA, George. Fronteiras da Educação: desigualdades, tecnologias e políticas. Editora da PUC Goiás, p.93-99, 2010.

RODRIGUES, Marta M. Assunção. Políticas Públicas. São Paulo: Publifolha, Coleção Folha Explica, 2010. ISBN 978-85-7914-153-9.

SARAIVA, C. Novo PNE: uma sistematização da contra reforma do ensino superior. CSPConlutas - Central Sindical e Popular. 12/08/2011. Disponível em: <http:// cspconlutas.org.br/2011/08/texto-formacao-setorial-educacao-novo-pne-uma-sistematizacaoda-contra->. Acesso em: 8 nov. 2014.

SAVIANI, Dermeval. Da nova LDB ao FUNDEB: por uma outra política educacional. Campinas, Autores Associados, 2007.

SOUZA, João Francisco de. Atualidade de Paulo Freire: contribuições ao debate sobre a educação na diversidade cultural. Biblioteca freireana; v. 3. São Paulo: Cortez, 2002.

SUDBRACK, Edite Maria (Org.). Políticas Educacionais: condicionantes e embates na educação básica. Frederico Westphalen: URI, 2014.

SUDBRACK, Edite Maria. Rosa-dos-ventos: traços da formação docente pós-LDB. Porto Alegre, Editora da UFRGS. Série Política e Gestão da Educação, 2009.

TEODORO, António. A educação em tempos de globalização neoliberal: os novos modos de regulação das políticas educacionais. Brasília: Liber Livro, 2011.

VALOURA, Leila de Castro. Paulo Freire: o educador brasileiro autor do termo empoderamento, em seu sentido transformador. Otics Rio, 2006. Disponível em: http://www.otics.org/estacoes-de-observacao/rio-saude-presente/subpav/promocao-dasaude/cpai/CPAI\%20-\%20Leituras\%20interessantes/paulo-freire-o-educador-brasileiroautor-do-termo-empoderamento-em-seu-sentido-transformador/at_download/file. Acesso em 30 maio 2015.

WEYH, Cênio Back. Educar pela participação. Santo Ângelo: FURI, 2011.

WIZIACK, João Carlos. O Ensino Superior no PNE: ideais estabelecidos para a "década da educação" e compromissos renovados para o período de 2011 a 2020. Dissertação (Mestrado em Educação). 200f. Universidade Metodista de Piracicaba. Piracicaba, 2010. Disponível em: https://www.unimep.br/phpg/bibdig/pdfs/docs/28112011_154339_dissertacaofinal.pdf Acesso em: 30 maio 2015.

ZANARDINI, João. Plano nacional de educação - PNE (2011 - 2020): algumas considerações. Universidade estadual do oeste do Paraná - Unioeste Campus de Cascavel, 2011. Disponível em: http://www.uffs.edu.br/ forgradsul/files/Joao\%20Zanardini\%20_ 
UNIOESTE_\%20_\%20Plano\%20Nacional\%20de\%20Educacao\%20_\%20PNE\%202011_20 20.pdf. Acesso em 30.05.2015. 